think, to a small-type appendix ; after all, there must be some limit to a subject which, like forensic medicine, reaches for support into so many other departments of both science and medical practice.

Glaister remains a fine textbook, a sound piece of writing, well documented from the current literature, extensively illustrated by case reference, balanced and authoritative. It is a book for the advanced student, the forensic pathologist and the criminal bar.

C.K.S.

\section{AN INTRODUCTION TO PATHOLOGY}

By G. Payling Wright, D.M., F.R.C.P. Pp. $x+$ 569 , illustrated. London: Longmans Green and Co. 1950. 30s.

In this age of increasing specialization the bewildered teachers of medical students are incessantly bidden to integrate the curriculum, to bridge gaps and to prune the ever-growing body of knowledge with which the student is presented. At no stage is this more difficult or important than in the transition from pre-clinical to clinical studies; the abnormal must be appreciated in terms of perverted normal function. General pathology is the best medium whereby this can be accomplished. Professor Payling Wright's new book, which bears all too modest a title, succeeds admirably in its project of orientating the student in his study of the fundamental aspects of disease. Stress is laid upon the causative factors, and the mechanisms whereby structural changes are brought about are clearly explained in the light of experimental research. The text is a model of clear exposition and is excellently illustrated by photographs and diagrams. Abundant references to original papers are supplied, both recent and old, reflecting the author's appreciation of the history of the subject. About twofifths of the book is devoted to neoplastic disease and the remainder deals with the principal groups in general pathology. There is a useful chapter on tissue reactions in virus infections, and the modifying action of the antibiotics in inflammation is discussed.

The student who digests this book will be well equipped for his professional work since he will approach his patients with the essential intellectual background necessary for the interpretation of disease. There are many teachers, too, who will welcome and be helped by this modern presentation of general pathology.

D.S.R.

\section{MODERN PRACTICE IN DERMATOLOGY}

Edited by G, B. Mitchell-HegGs, O.B.E., M.D., F.R.C.P. Pp. xxv +836 , with 3 I 9 illustrations and 7 coloured plates. London : Butterworth $\&$ Co. 1950. $£ 33$ s.

This impressive volume is beautifully produced with a wealth of excellent photographic illustrations.
The 50 separate chapters are the work of no less than 40 different authors, so it would be impossible 3 to expect a uniform quality throughout. Some off the chapters are up to date and authoritative, whilst . others would be suitable only for undergraduate: teaching. In such a work some overlapping is also inevitable; for instance, two consecutive chapters describe impetigo and its treatment. In both, the local use of penicillin is advocated, whichen will doubtless come in for some criticism. Histologyo is dealt with, for the most part, sketchily but throughout a practical outlook has been maintainedis

This book will not replace the present text books $\overrightarrow{0}$ being too full for the use of the average undergraduate. It will, however, be valuable to practi $\vec{w}$ tioners interested in the subject, particularly to those who are isolated from teaching centres ofo libraries.

\section{THE ANATOMY OF THE FEMALE PELVIS}

By F. A. Maguire, C.M.G., D.S.O., V.D., M.D. i Ch.M., F.R.C.S., F.R.A.C.S., F.R.C.O.G., F.A.C.S. 4th Edition. Pp. $x v+176$, with $55^{\circ}$ illustrations. London: H. K. Lewis. 1949을 $42 s$.

The author, having been for some years professoro of anatomy, combines both clinical and anatomica $\bar{b}$ knowledge. The result is excellent. This fourth edition has been thoroughly revised, with addition of many new illustrations, and present detailed study of the entire pelvic anatomy. Thato of the vaginal and uterine supports is particulactyo clearly described, whilst a contribution by Dr. Barrington on the examination of the gynaecologica case is thoroughly sound. The production is attractive.

This book is well worthy of study; for the student as a book of reference, for the budding gynaecologist as a constant companion.

\section{PRACTICAL PROCEDURES IN CLINICAL MEDICINE}

By R. I. S. BaYlis, M.A., M.D., M.R.C.P. Pp. viio +445 , with 62 illustrations. London: J. and $A .3$ Churchill, Ltd. 1950. 25 s.

A generous welcome should be given to this excellent book, which fills a very real need in hos- 윽 pital and general practice today.

It has been well said that dull tasks are amongst the most difficult to perform efficiently. In the field of medical writing, one can imagine few mores difficult undertakings than completing a volume on practical clinical procedures, which is both in N formative and easy to read, and which bears the stamp of originality of form and presentation. Dr? Bayliss has been uncommonly successful in achievto ing all these goals which have been realized almost single-handed, and he is to be congratulated on the result of his efforts.

The reader will be surprised at the extensive 